\title{
Electrocardiographic and hemato-biochemical effects of two balanced anesthetic protocols in dogs
}

\author{
Anubhav Khurana, Adarsh Kumar, Sandeep Kumar Sharma and Amit Kumar \\ Department of Veterinary Surgery and Radiology, Dr. G.C. Negi College of Veterinary and Animal Sciences, \\ CSKHPKV, Palampur, Himachal Pradesh, India. \\ Corresponding author: Anubhav Khurana, e-mail: anubhav.khurana@gmail.com, Ak: adarsh9kan@gmail.com, \\ SKS: sandeepsharma956@gmail.com, AK: drasingla@gmail.com \\ Received: 30-06-2014, Revised: 08-09-2014, Accepted: 13-09-2014, Published online: 18-10-2014
}

doi: 10.14202/vetworld.2014.835-841. How to cite this article: Khurana A, Kumar A, Sharma SK, Kumar A (2014) Electrocardiographic and haemato-biochemical effects of two balanced anesthetic protocols in dogs, Veterinary World 7(10): 835-841.

\begin{abstract}
Aim: The purpose of this study was to compare the electrocardiographic (ECG), hematological and clinico-biochemical effects of two balanced anesthetic protocols in dogs.

Materials and Methods: A total of 20 clinical cases of dogs, randomly divided into two groups of 10 animals each were made part of study. All dogs were premedicated with injection atropine sulfate @ $0.04 \mathrm{mg} / \mathrm{kg}$ body weight (b. wt.) subcutaneously followed 15 min later with injection butorphanol tartarate @ 0.2 mg/kg b. wt. intravenous (IV). Subsequently after 10 min premedicated with injection diazepam @ $0.5 \mathrm{mg} / \mathrm{kg}$ b. wt. IV (Group DP) or injection acepromazine maleate @ $0.015 \mathrm{mg} / \mathrm{kg}$ b. wt. IV (Group AP) followed by injection propofol "till effect" IV for induction of surgical anesthesia. The animals were immediately transferred to halothane in oxygen. Observations recorded in dogs included ECG recordings, hematological and clinico-biochemical observations at various time intervals.
\end{abstract}

Results: No arrhythmia was observed in any animal pre-operatively and intra-operatively in any of the groups. Significant fall in packed cell volume (PCV) and total erythrocyte count occurred in DP group in early phase, whereas only PCV decreased significantly in AP group. Biochemical parameters were non-significant in both the groups.

Conclusion: Both diazepam-butorphanol-propofol-halothane and acepromazine-butorphanol-propofol-halothane are safe with respect to their ECG, hematological and biochemical effects in clinical cases.

Keywords: acepromazine, butorphanol, diazepam, dog, propofol.

\section{Introduction}

Small animals are most often placed under general anesthesia due to the types of procedures typically performed, the small size of the patient, their suitability to general anesthesia, and the greater degree of control. A balanced anesthesia protocol can be used whereby different drugs with different effects are used and hence that a high dose of just one drug can be avoided. Premedication plays an important role in this respect, because analgesic and myorelaxant effects of substances used for premedication may have prime importance for the whole anesthesia. The combination of complementary drugs permits use of a decreased dose of each drug to achieve anesthesia and decreases their commensurate side effects. These requirements are often met when neuroleptanalgesic combinations - The combination of a neuroleptic drug with sedative properties and an opioid analgesic drug are used. Combinations of diazepam-butorphanol and acepromazine-butorphanol are routinely used as preanesthetic to general anesthesia in dogs.

Propofol is one of the most common anesthetics used in present-day medicine [1]. Propofol is also a

Copyright: The authors. This article is an open access article licensed under the terms of the Creative Commons Attributin License (http:// creative commons.org/licenses/by/2.0) which permits unrestricted use, distribution and reproduction in any medium, provided the work is properly cited. reliable, safe and prompt anesthetic agent when used during induced cardiovascular and pulmonary-impaired conditions without surgery, or to induce anesthesia prior to inhalant anesthesia with and without surgery. In addition, the drug has antioxidant properties (propofol-nitrous oxide) secondary to its phenol-based chemical structure [2]. Halothane (2-bromo-2-chloro-1,1,1-trifluoroethane), a halogenated hydrocarbon, is an inhalational anesthetic agent that has been widely used as an induction and maintenance volatile anesthetic since introduced into clinical practice in 1957 [3]. Halothane anesthesia has been reported to be possibly the most commonly used inhalational anesthetic in many developing countries [4].

Several drugs used in anesthesia interfere with the cardiac rhythm. As a rule, those effects of the anesthetics on the cardiac conduction system, such as those promoted by drugs like acetylcholine or opioids are well known. On the other hand, careful studies on more recent drugs are lacking and their effects are not completely understood [5]. Both anesthetic drugs and surgical procedure have variety of effects on blood hemato-biochemistry. These alterations are particularly important in clinical patients which may have underlying conditions.

Keeping in view the above, the goal of this study was to clinically evaluate electrocardiographic (ECG), hematological and clinico-biochemical effects 
of diazepam and acepromazine along with butorphanol in propofol induction and halothane maintenance anesthesia as balanced anesthesia protocol in canines.

\section{Materials and Methods \\ Ethical approval}

The research program was conducted after the approval of the Institutional Animal Ethics Committee, CSKHPKV, Palampur (H.P).

\section{Location and Clinical programme of work}

Clinical cases of dogs of either sex presented to the Teaching Veterinary Clinical Complex of the college for various surgical affections were made the subjects of the study. The dogs were subjected to a detailed physical examination and were categorized according to surgical procedures performed and American Society of Anesthesiologists Classifications (Table-1). The area of saphenous and recurrent tarsal veins in all the limbs were prepared aseptically for administration of drugs as well as for collection of blood samples along with intravenous (IV) catheterization, delivering injection ringer lactate. All dogs were premedicated with injection. Atropine sulfate @ $0.04 \mathrm{mg} / \mathrm{kg}$ body weight (b. wt.) followed 15 min later with injection butorphanol tartarate @ $0.2 \mathrm{mg} / \mathrm{kg}$ b. wt IV. Subsequently after 10 min pre-medicated with injection diazepam @ 0.5 mg/kg b. wt IV (Group DP, n=10) or injection. acepromazine maleate @ 0.015 mg $/ \mathrm{kg}$ b. wt. IV (Group AP, $\mathrm{n}=10$ ). After 5 min anesthesia was induced with injection. Propofol (3.0-5.0 mg/kg) by IV injection "till effect." Then endotracheal intubation was done and animals were connected to the anesthetic machine (co-axial circuit with carbon dioxide absorber [Anesthetic machine: Moduflex co-axial Circuit, Dispomed Ltd. Canada]) with halothane vaporizer till the end of surgery. Oxygen flow rates were set according to b. wt. of the animal. The groups were evaluated on the basis of the following parameters: ECG, hematological and biochemical observations.

Table-1: Patient classification.

\begin{tabular}{lcc}
\hline & DP group & AP group \\
\hline Signalment & & \\
Mean age (months) & $25.5 \pm 4.63$ & $29.00 \pm 8.83$ \\
Gender & 2 & 7 \\
Male & 8 & 3 \\
Female & $14.58 \pm 2.01$ & $17.99 \pm 1.50$ \\
Mean b.wt (kg) & & \\
Categorized surgical & & 6 \\
procedures & 9 & 2 \\
Elective surgeries & 1 & 1 \\
Orthopedic surgeries & - & 1 \\
Tumor excision & - & 6 \\
Others & & 3 \\
Physical status & 9 & 1 \\
ASA 1 & - & 10 \\
ASA 2 & 1 & \\
ASA 3 & 10 & \\
Total &
\end{tabular}

b. wt=Body weight, $A S A=$ American Society of Anesthesiologists

\section{ECG observations}

Animals were positioned on a non-conductive surface in right lateral recumbency with forelimbs perpendicular to the long axis of the body. ECG was obtained using lead II system (1 mv=1 cm $25 \mathrm{~mm} / \mathrm{s})$. The animals were monitored by continued computerized ECG using multi parameter monitor (BPL India, Ltd., New Delhi, India). ECG tracings were taken at regular time intervals i.e., $\mathrm{T}_{0 \text { min }}(\mathrm{min}), \mathrm{T}_{1 \mathrm{~min}}, \mathrm{~T}_{5 \text { min, }}$, $T_{15 \text { min }}, T_{30 \text { min }}$ and $T_{45 \text { min }}$ (Table-2). Development of arrhythmias were observed and following time and voltage function components of ECG were recorded from tracings: P interval, QRS interval, QT interval, $\mathrm{T}$ interval, ST segment elevation and depression from base line, PR segment, P amplitude, R amplitude, QRS amplitude, T amplitude.

\section{Hematological observations}

The blood samples collections were made at base line, early phase and late phase as per Table-3. To evaluate hematological parameters, venous blood (0.5-1 ml) of each animal was collected in EDTA vials. The hematological parameters estimated were hemoglobin ( $\mathrm{Hb})$, packed cell volume (PCV), total erythrocyte count (TEC). The samples were analyzed using blood cell counter (Blood Cell Counter: BC-2800 vet, Auto Hematology Analyzer, Mindray).

\section{Biochemical observations}

A volume of $5 \mathrm{ml}$ of venous blood was collected in heparinized vials. Plasma was separated by centrifugation at $2500 \mathrm{rpm}$ for $15 \mathrm{~min}$. The blood glucose was estimated immediately by digital glucometer (Blood Glucose Monitor: Bayer contour, Bayer AG). The various plasma attributes and enzymes estimated were: Aspartate aminotransferase (AST), alanine aminotransferase (ALT), blood urea nitrogen (BUN), creatinine (CRTN), total protein (TPR) and alkaline phosphatase and plasma chloride using

Table-2: Time interval for recording various observations.

\begin{tabular}{ll}
\hline Time interval & Time/ stage \\
\hline$T_{0}$ & $\begin{array}{l}\text { Base value (before administration } \\
\text { of anesthetic drug) } \\
\text { Just after induction and start of } \\
\text { halothane maintenance }\end{array}$ \\
$T_{1}$ & 5 min post halothane \\
$T_{5}$ & 15 min post halothane \\
$T_{15}$ & 30 min post halothane \\
$T_{30}$ & 45 min post halothane \\
\hline
\end{tabular}

Table-3: Time interval for hemato-biochemical observations.

\begin{tabular}{ll}
\hline Time interval & Time/ stage \\
\hline Base line & Base value (before anesthesia) \\
Early phase & $\begin{array}{l}\text { Intraoperative (at } \mathrm{T}_{30} \text { i.e., } \\
\text { (30 min post halothane) }\end{array}$ \\
Late phase & Post-operative (after extubation) \\
\hline
\end{tabular}


commercially available kits on semi-automatic blood chemistry analyzer (Blood Chemistry Analyzer: (RA-50), Bayer Diagnostics, Gujarat-India). Plasma sodium and potassium $(\mathrm{K})$ were estimated on flame photometer (Flame Photometer: Flame Photometer 129, Systronics, Gujarat-India).

\section{Statistical analysis}

The statistical analysis of data was performed with SAS 9.2 by SAS Institute Inc., Cary. NC. USA, using simple t-test. The paired t-test was used to compare the mean values at different intervals with their base values in each group. $\mathrm{p}<0.05$ and $\mathrm{p}<0.01$ were considered as significant.

\section{Results}

\section{ECG effects}

The ECG parameters during anesthesia in both the groups are depicted in Tables- 4 and 5. No arrhythmia was observed in any animal pre-operatively and intra-operatively in any of the groups. There was significant increase in QT interval at $\mathrm{T}_{15}(\mathrm{p}<0.05), \mathrm{T}_{30}$ $(\mathrm{p}<0.05)$ and at $\mathrm{T}_{45}(\mathrm{p}<0.01)$ in AP group. Significant $(\mathrm{p}<0.05)$ increase in $\mathrm{P}$ amplitude was recorded just after induction in AP group. Furthermore, significant $(p<0.05)$ increase in PR segment was recorded at $\mathrm{T}_{30}$ in AP group. In one animal in DP group, wandering sinus pacemaker was present at $\mathrm{T}_{1}$ and $\mathrm{T}_{5}$ (Figure-1a-c). Diphasic T waves were also present in this dog after induction until the end of the anesthetic period. ST elevation was noticed in an animal in AP group, 5 min after induction and start of halothane maintenance, which sustained till $\mathrm{T}_{45}$ (Figure-1d and e). Generally spiked hyperkalemic $\mathrm{T}$ waves were noticed in another dog in AP group (Figure-1f and $g$ ). $T$ waves at $T_{0}$ and $T_{5}$ were normal, while at $\mathrm{T}_{15}, \mathrm{~T}_{30}$ and $\mathrm{T}_{45}$ peaked $\mathrm{T}$ waves were present. Plasma potassium levels in this dog were; before anesthesia $4.0 \mathrm{mmol} / \mathrm{L}$, during anesthesia $7.0 \mathrm{mmol} / \mathrm{L}$ and after anesthesia $7.0 \mathrm{mmol} / \mathrm{L}$.

\section{Hematological and biochemical observations}

In both the groups, there was non-significant fall in $\mathrm{Hb}$ in early phase which later recouped but values were lower than the base line (Table-6). There was significant fall in PCV at early phase in both the groups with $(\mathrm{p}<0.01)$ in DP and $(\mathrm{p}<0.05)$ in AP group respectively. Similarly TEC showed significant decrease at early phase $(p<0.01)$ and late phase $(p<0.05)$ in DP group. All the changes were within clinically normal ranges. Inter group comparison showed non-significant difference between values of Hb, PCV and TEC.

Mean \pm standard error values of biochemical observations in both the groups at different time intervals are illustrated in Table-7. During the present study, in general, the changes in biochemical parameters were observed to be non-significant. Glucose showed non-significant decrease from base line values in both the groups at early phase. At late phase glucose levels increased non-significantly in comparison to early phase. There was non-significant decrease in AST in both the groups and ALT in DP group. Intergroup comparison showed significant $(\mathrm{p}<0.05)$ difference between late phase values of TPR. Significant difference $(p<0.05)$ was also found in CRTN early phase values and late phase $(p<0.01)$. Chloride values were also significant $(p<0.05)$ at early phase between two groups.

\section{Discussion}

This clinical study was carried out to clarify and compare the degree of influence of anesthetic agents commonly used during anesthesia on the heart conduction systems of dogs, with or without the presence of ECG changes in the pre-anesthetic ECG. Effects on blood hematology and biochemistry were also observed. A total of twenty animals were randomly and equally divided into two groups DP and AP of 10 animals each.

ECG was overall normal in both the groups and significance cannot be attached to some of the changes in time and voltage parameters of ECG. Wandering sinus pacemaker is a frequent normal finding in dogs [6]. Diphasic T waves in the animal correlated with intraoperative hypokalemia [6]. Plasma potassium levels in this dog were; base line $6.0 \mathrm{mmol} / \mathrm{L}$, early phase $3.3 \mathrm{mmol} / \mathrm{L}$ and late phase $3.6 \mathrm{mmol} / \mathrm{L}$. Reference ranges for canine plasma potassium are 3.6-6.0 mmol/L [7]. Anesthetic induced myocardial

Table-4: Mean \pm SE values of ECG variables during anesthesia in group DP $(n=10)$ and AP $(n=10)$ at different time intervals in dogs.

\begin{tabular}{|c|c|c|c|c|c|c|c|c|}
\hline \multirow{2}{*}{$\begin{array}{l}\text { Time } \\
\text { interval } \\
\text { ( } \mathrm{min} \text { ) }\end{array}$} & \multicolumn{2}{|c|}{ P interval (s) } & \multicolumn{2}{|c|}{ QRS interval (s) } & \multicolumn{2}{|c|}{ QT interval (s) } & \multicolumn{2}{|c|}{ T interval (s) } \\
\hline & DP & $\mathbf{A P}$ & DP & $\mathbf{A P}$ & DP & $\mathbf{A P}$ & DP & $\mathbf{A P}$ \\
\hline $\mathrm{T}_{0}$ & $0.04 \pm 0.001$ & $0.047 \pm 0.005$ & $0.058 \pm 0.006$ & $0.051 \pm 0.002$ & $0.172 \pm 0.017$ & $0.181 \pm 0.008$ & $0.056 \pm 0.006$ & $0.058 \pm 0.007$ \\
\hline $\mathrm{T}_{1}$ & $0.043 \pm 0.002$ & $0.047 \pm 0.003$ & $0.054 \pm 0.003$ & $0.049 \pm 0.002$ & $0.168 \pm 0.018$ & $0.180 \pm 0.005$ & $0.051 \pm 0.005$ & $0.065 \pm 0.005$ \\
\hline $\mathrm{T}_{5}$ & $0.044 \pm 0.003$ & $0.047 \pm 0.003$ & $0.056 \pm 0.003$ & $0.052 \pm 0.003$ & $0.200 \pm 0.010$ & $0.197 \pm 0.007$ & $0.064 \pm 0.007$ & $0.076 \pm 0.010$ \\
\hline $\mathrm{T}_{15}$ & $0.043 \pm 0.001$ & $0.057 \pm 0.003$ & $0.052 \pm 0.003$ & $0.050 \pm 0.002$ & $0.198 \pm 0.006$ & $0.202^{\mathrm{a}} \pm 0.005$ & $0.063 \pm 0.007$ & $0.064 \pm 0.011$ \\
\hline $\mathrm{T}_{30}$ & $0.04 \pm 0.001 * *$ & $0.05 \pm 0.003$ & $0.054 \pm 0.003$ & $0.047 \pm 0.002$ & $0.219 \pm 0.010$ & $0.215^{\mathrm{a}} \pm 0.008$ & $0.060 \pm 0.009$ & $0.080 \pm 0.01$ \\
\hline $\mathrm{T}_{45}$ & $0.038 \pm 0.002 * *$ & $0.055 \pm 0.004$ & $0.056 \pm 0.002$ & $0.055 \pm 0.004$ & $0.203 \pm 0.007$ & $0.217^{\mathrm{ab}} \pm 0.007$ & $0.068 \pm 0.012$ & $0.080 \pm 0.008$ \\
\hline
\end{tabular}

The mean difference from base value is significant $(p<0.05)$, ${ }^{a b}$ The mean difference from base value is

significant $(p<0.01), * *$ The mean difference between the groups is significant $(p<0.01), S E=S t a n d a r d$ error, $\mathrm{ECG}=$ Electrocardiographic 


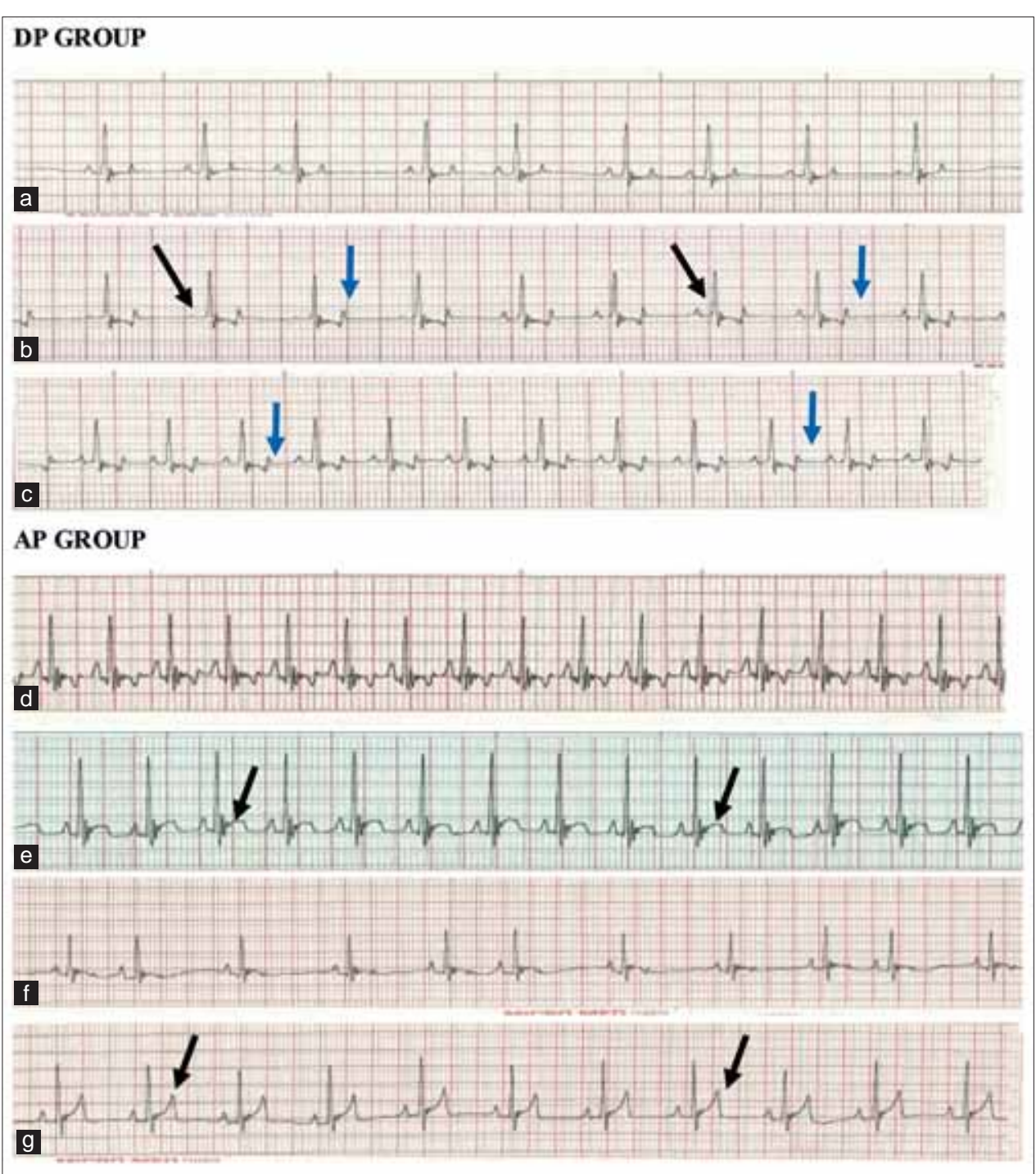

Figure-1: Electrocardiographic findings, (a) At $T_{0}$ normal electrocardiographic, normal $P$ waves and $T$ waves, (b) At $T_{5}$ wandering sinus pacemaker (black arrows) is evident and diphasic T waves (blue arrows), (c) At $T_{15}$ absence of wandering sinus pacemaker and diphasic T waves are still presented, (d) Normal ST segment at $T_{0}$, (e) At T5 elevation in ST segment was observed (black arrows), (f) At $T_{0}$ normal $T$ waves, ( $g$ ) At $T_{15}$ typically spiked hyperkalemic $T$ waves present (black arrows).

hypoxia may have caused ST elevation [6]. Marked ST-segment elevation in the right precordial leads in propofol anesthesia has been reported in humans too [1]. Spiked T waves may have been caused by intraoperative hyperkalemia [6]. Plasma potassium levels in this dog were; before anesthesia $4.0 \mathrm{mmol} / \mathrm{L}$, during anesthesia $7.0 \mathrm{mmol} / \mathrm{L}$ and after anesthesia $7.0 \mathrm{mmol} / \mathrm{L}$. Spiked T waves and biphasic $\mathrm{T}$ waves were also observed in xylazine-propofol anesthesia in dogs [8].

Prolonged QT interval can occur in hypothermia and bradycardia [6]. There is inverse relationship between QT interval and heart rate $[9,10]$. Similarly, propofol induced increase in the means of PQ, QRS and QT intervals with decrease in heart rate and arterial blood pressure were observed in dogs [11], whereas decrease in QT interval has been reported in goats [12]. Dennis et al. [13] compared the effects of propofol and thiopentone on ECG of dogs and found that propofol induced a comparatively lesser increase in QT and ST intervals. Furthermore, halothane has been reported to prolong QT interval in humans [14]. Therefore, increase in QT interval in present study may have been due to bradycardia, anesthetic caused hypothermia or propofol and halothane caused increase.

Decrease in $\mathrm{Hb}$ intra-operatively may be because whether or not animals are anemic prior to the operative procedure, $\mathrm{Hb}$ concentrations will be decreased intraoperatively by anesthetic-induced vasodilation, splenic dilation, non-Hb-containing fluid administration and blood loss [7]. Similarly, Naghibi et al. [15] reasoned that due to vasodilation at the level of microcirculation and passage of many red blood cell (RBC's) from circulation may cause decrease in $\mathrm{Hb}$ level measured in peripheral veins, which is also called as plasma skimming. Pooling of circulatory blood cells in the spleen or other reservoirs secondary to sympathetic activity may explain the decrease in $\mathrm{Hb}, \mathrm{PCV}$ and total leukocyte count [16]. 


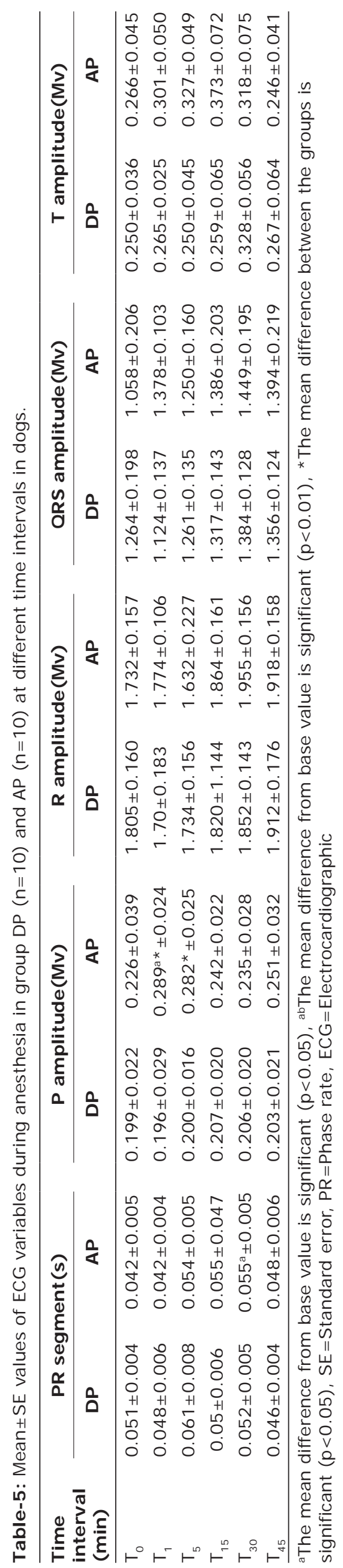

Results of this study are in consistence with previous studies. Gill et al. [17] reported decrease in hematocrit, $\mathrm{Hb}$ and RBC count values and an increase in white blood cell count values after surgery was performed under acetylpromazine-propofol anesthesia in dogs. Similarly, decrease in Hb, PCV and TEC has been reported in diazepam-propofol anesthesia in dogs [18]. Whereas, no change in PCV and a decrease in $\mathrm{Hb}$, TEC and TLC till $15^{\text {th }}$ min after induction of anesthesia with propofol and then a gradual rise towards the pre induction levels was observed [19]. Halothane induced significant decrease in PCV, Hb and plasma protein was also observed in dogs [20]. Thus combined effects of propofol, halothane with anesthetic induced change may have decreased $\mathrm{Hb}$, PCV and TEC in the present study.

Hypoglycemia may have occurred as a non-specific hormonal response to the stress of anesthesia and operation [7]. Previous studies have reported hyperglycemia with use of propofol [21]. There were no deleterious effects of halothane on liver transaminases in this study rather AST values decreases intraoperatively. Kwon et al. [22] observed decrease in AST and ALT values within clinically normal range and non-significant change in BUN and CRTN levels during propofol anesthesia in dogs, when propofol anesthesia was induced and maintained for 7 consecutive days in dogs. No alterations in biochemical parameters (except hyperglycemia) in dogs under propofol anesthesia have been published by Mukati et al. [21]. Halothane or its metabolites could cause a mild increase in liver enzymes suggestive of sub-clinical liver cell alteration which buttresses the fact that halothane anesthesia is still a safe agent in patients without pre-existing liver disease. Halothane induced elevation in serum liver enzymes have been reported in dogs [23], in camels [24]. Better blood supply to liver due to propofol administration may have caused decrease in ALT and AST as observed in this study.

In the present study, there was no significant difference in plasma electrolyte concentrations during propofol-halothane anesthesia in all groups, which indicated that electrolyte balance is not altered. Halothane has been reported not to cause any significant alteration in the level of plasma sodium and potassium in buffaloes also [25].

\section{Conclusion}

Both the anesthetic combinations i.e., diazepam-butorphanol-propofol-halothane and acep romazine-butorphanol-propofol-halothane produced no arrhythmia. Prolongation of QT interval was observed in AP group, however it is clinically acceptable. Significant fall in PCV and TEC occurred in DP group in early phase, whereas only PCV decreased significantly in AP group. These changes were within clinically normal ranges. No significant biochemical changes were observed. 
Table-6: Effects of DP $(n=10)$ and AP $(n=10)$ anaesthetic drug combinations on various haematological parameters during early and late phase in dogs (mean $\pm \mathrm{SE})$.

\begin{tabular}{|c|c|c|c|c|c|c|}
\hline \multirow{2}{*}{$\begin{array}{l}\text { Time } \\
\text { (phases) }\end{array}$} & \multicolumn{2}{|c|}{ Hb (g \% ) } & \multicolumn{2}{|c|}{ PCV (\%) } & \multicolumn{2}{|c|}{$\operatorname{TEC}\left(10^{12} / \mu \mathrm{l}\right)$} \\
\hline & DP & AP & DP & AP & DP & AP \\
\hline Base line & $14.02 \pm 0.49$ & $13.20 \pm 0.53$ & $40.68 \pm 1.26$ & $41.1 \pm 1.42$ & $6.37 \pm 0.22$ & $5.54 \pm 0.54$ \\
\hline Early phase & $13.06 \pm 0.44$ & $11.85 \pm 0.65$ & $31.52 \pm 2.47^{\mathrm{ab}}$ & $34.5 \pm 1.90^{\mathrm{a}}$ & $4.74 \pm 0.30^{\mathrm{ab}}$ & $4.70 \pm 0.61$ \\
\hline Late phase & $12.98 \pm 0.34$ & $12.05 \pm 0.62$ & $33.87 \pm 3.07$ & $37.2 \pm 2.04$ & $5.31 \pm 0.38^{a}$ & $5.06 \pm 0.46$ \\
\hline
\end{tabular}

The mean difference from base value is significant $(p<0.05)$, ab The mean difference from base value is

significant $(p<0.01), * *$ The mean difference between the groups is significant $(p<0.01)$. PCV=Packed cell volume,

$\mathrm{TEC}=$ Total erythrocyte count, $\mathrm{Hb}=$ Hemoglobin, $\mathrm{SE}=$ Standard error

Table-7: Effects of DP $(n=10)$ and AP $(n=10)$ anaesthetic drug combinations on various biochemical parameters during early and late phase of study in dogs (mean \pm SE).

\begin{tabular}{|c|c|c|c|c|c|c|}
\hline \multirow[t]{2}{*}{ Variables } & \multicolumn{3}{|c|}{ DP } & \multicolumn{3}{|c|}{ AP } \\
\hline & Base line & Early phase & Late phase & Base line & Early phase & Late phase \\
\hline Glu (mg/dl) & $98.16 \pm 6.05$ & $87.06 \pm 7.99$ & $109.3 \pm 14.41$ & $77.3 \pm 4.46$ & $69.9 \pm 4.01$ & $83.4 \pm 6.89$ \\
\hline CRTN (mg/dl) & $1.04 \pm 0.17$ & $1.06 \pm 0.17 *$ & $1.05 \pm 0.18 * *$ & $1.44 \pm 0.06$ & $1.48 \pm 0.06$ & $1.61 \pm 0.06$ \\
\hline BUN (mg/dl) & $19.64 \pm 4.03$ & $16.49 \pm 2.94$ & $21.00 \pm 5.64$ & $22.52 \pm 0.25$ & $22.49 \pm 0.28$ & $22.82 \pm 0.19$ \\
\hline TPR (mg/dl) & $5.88 \pm 0.52$ & $5.64 \pm 0.54$ & $5.51 \pm 0.32 *$ & $6.74 \pm 0.21$ & $6.23 \pm 0.20$ & $6.41 \pm 0.24$ \\
\hline $\operatorname{ALT}(I \cup / L)$ & $38.4 \pm 4.45$ & $31.1 \pm 4.08$ & $34.1 \pm 4.39$ & $36.2 \pm 2.95$ & $37.0 \pm 2.83$ & $32.2 \pm 2.35$ \\
\hline AST (IU/L) & $48.3 \pm 12.3$ & $35.6 \pm 11.6$ & $50.0 \pm 15.13$ & $33.8 \pm 3.19$ & $27.1 \pm 2.09$ & $26.4 \pm 1.77$ \\
\hline $\operatorname{ALKP}(I U / L)$ & $74.9 \pm 11.7$ & $74.7 \pm 11.9$ & $72.9 \pm 8.24$ & $75.2 \pm 16.9$ & $68.1 \pm 12.7$ & $70.1 \pm 15.4$ \\
\hline Chloride $(\mathrm{mmol} / \mathrm{L})$ & $107.6 \pm 4.55$ & $112.3 \pm 2.99 *$ & $106.7 \pm 2.66$ & $119.7 \pm 2.23$ & $126.1 \pm 5.42$ & $115.8 \pm 3.56$ \\
\hline Sodium (mmol/L) & $138.0 \pm 4.12$ & $138.7 \pm 3.56$ & $142.0 \pm 3.29$ & $143.2 \pm 2.60$ & $140.6 \pm 3.61$ & $137.3 \pm 1.49$ \\
\hline Potassium (mmol/L) & $4.16 \pm 0.263$ & $4.04 \pm 0.239$ & $4.08 \pm 0.243$ & $4.47 \pm 0.18$ & $4.24 \pm 0.192$ & $4.13 \pm 0.130$ \\
\hline
\end{tabular}

aThe mean difference from base value is significant $(p<0.05)$, abThe mean difference from base value is significant $(p<0.01)$, *The mean difference between the groups is significant $(p<0.05)$, ** The mean difference between the groups is significant $(p<0.01)$. CRTN=Creatinine, $B U N=B l o o d$ urea nitrogen, TPR=Total protein, ALKP=Alkaline phosphatase, $\mathrm{AST}=$ Aspartate aminotransferase, $\mathrm{ALT}=$ Alanine aminotransferase, $\mathrm{SE}=$ Standard error

Thus, both combinations are safe with respect to their ECG, hematological and biochemical effects in clinical cases.

\section{Authors' Contributions}

$\mathrm{AKh}$ performed the research and drafted the manuscript, $\mathrm{AKu}$ and SKS conceived, designed and supervised the study, AmK did statistical analysis and proof read the manuscript. All authors read and approved the final manuscript.

\section{Acknowledgments}

The authors are thankful to the Head, Department of Veterinary Surgery \& Radiology, Dr. G.C. Negi COVAS, CSKHPKV for providing necessary facilities. The work was carried out using the institutional fund provided by University.

\section{Competing I nterests} interests.

The authors declare that they have no competing

\section{References}

1. Vernooy, K., Delhaas, T., Olaf, L., Cremer, T.O., Diego, J.M.D., Timmermans, C., Volders, P.G., Prinzen, F.W., Crijns, H.J., Antzelevitch, C., Kalkman, C.J., Rodriguez, L.M. and Brugada, R. (2006) Electrocardiographic changes predicting sudden death in propofol-related infusion syndrome. Heart Rhythm., 3(2): 131-137.

2. Riera, A.R.P., Uchida, A.H., Schapachnik, E., Dubner, S., Filho, C.F. and Ferreira C. (2010) Propofol infusion syndrome and Brugada syndrome electrocardiographic phenocopy. Cardiol. J., 17(2): 130-135.

3. Eyelade, O.R., Adelaja, O.B., Nwobi, L.N. and Adedapo, K.S. (2013) Effect of halothane on liver enzymes after general anaesthesia. Int. J. Biol. Med. Res., 4(1): 2772-2775

4. Mahboobi, N., Esmaeili, S., Safari, S., Habibollahi, P., Dabbagh, A. and Alavian, S.M. (2012) Halothane: How should it be used in a developing country? East. Mediterr. Health. J., 18(2): 159-164.

5. Warpechowski, P., Santos, A.T.L., Pereira, P.J.I. and Lima, G.G. (2010) Effects of propofol on the cardiac conduction system. Rev. Bras. Anestesiol., 60(4): 438-444.

6. Tilley, L.P. (1992) Essentials of Canine and Feline Electrocardiography. Interpretation and Treatment. $3^{\text {rd }}$ ed. Lea \& Febiger, Philadelphia, London.

7. Tranquilli, W.J., Thurmon, J.C. and Frimm, K.A. (2007) Lumb and Jones' Veterinary Anesthesia and Analgesia. $4^{\text {th }}$ ed. Blackwell Publishing, Ames, IA.

8. Sooryadas, S., Amma, T.S., Rajankutty, K., Gopakumar, N. and Nayar, K.N.M. (2011) Electrocardiogram changes during xylazine-propofol anaesthesia in dogs: A clinical study. Indian J. Vet. Surg., 32(2): 129-130.

9. Sakaguchi, Y., Takahara, A., Nakamura, Y., Akie, Y. and Sugiyama, A. (2008) Halothane-anaesthetized, closedchest, guinea-pig model for assessment of drug-induced QT-interval prolongation. Basic Clin. Pharmacol. Toxicol., 104(1): 43-48.

10. Singh, G.D., Kinjavdekar, P., Amarpal, Aithal, H.P., Pawde, A.M., Zama, M.M.S., Singh, J. and Tiwary, R. (2013) Clinicophysiological and haemodynamic effects of fentanyl with xylazine, medetomidine and dexmedetomidine in isoflurane-anaesthetised water buffaloes (Bubalus bubalis). J. S. Afr. Vet. Assoc., 84(1): E1-E11.

11. Gunay, C. and Balikci, E. (2001) The comparison of effects of propofol and isoflurane on some clinical and 
electrocardiographic ECG findings in dogs. Kafkas Univ. Vet. Fak., 7: 87-93.

12. Madan, A.K., Korde, J.P., Das, A.K. and Rastogi, S.K. (2010) Propofol-induced electrophysiological changes in goats. Vet. Arh., 80(1): 27-39.

13. Dennis, S.G., Wotton, P.R., Boswood, A. and Flahery, D. (2007) Comparison of the effects of thiopentone and propofol on the electrocardiogram of dogs. Vet. Rec., 160(2): 681-686.

14. Whyte, S.D., Booker, P.D. and Buckley, D.G. (2005) The effects of propofol and sevoflurane on the QT interval and transmural dispersion of repolarization in children. Anesth. Analg., 100(1): 71-77.

15. Naghibi, K.H., Yaraghi, A. and Adibi, P. (2002) Haemoglobin and haematocrit changes during uncomplicated anesthesia: General anaesthesia and local anaesthesia. J. Res. Med. Sci., 7(4): 9.

16. Wagner, A.E., Muir, W.W. and Hinchiff, K.W. (1991) Cardiovascular effects of xylazine and detomidine in horses. Am. J. Vet. Res., 52(5): 651-657.

17. Gill, J.R., Rodriguez, J.F., Ezquerra, L.J., Vives, M.A., Jimenez, J. and Uson, J.M. (1996) Development of anaesthesia and changes in the blood parameters in dogs medicated with propofol. Med. Vet., 13: 242-246.

18. Suresha, L., Ranganath, B.N., Vasanth, M.S. and Ranganath, L. (2012) Haemato-biochemical studies on triflupromazine HCL and diazepam premedication for propofol anaesthesia in dogs. Vet. World, 5(11):672-675.
19. Bayan, H., Sarma, K.K. and Kalita, A. (2002) A note on the induction of general anaesthesia with propofol in canine. Indian Vet. Med. J., 26: 173-174.

20. Lukanc, B., Seliskar, A., Pecar, J. and Butinar, J. (2002) Halothane anaesthesia in comparison with combined intravenous anaesthesia by midazolam and butorphanol in dogs. Slov. Vet. Res., 39(1): 69-83.

21. Mukati, B.D., Singh, V. and Shukla, B.P. (2004) Clinical, physiological and haematological studies on propofol as general anaesthesia with xylazine. Paper Presented at $28^{\text {th }}$ Congress of Indian Society of Veterinary Surgery held at Jabalpur, wef. Nov, 18-20. p78-79.

22. Kwon, Y.S., Jang, K.H., Kim, J.A.E., Chae, H.G., Lim, J.H., Lee, K.W. and Jang, I.H. (1998) Effects of continuous administration of propofol in dogs. Korean J. Vet. Clin. Med., 16: 363-368.

23. Topal, A., Gul, N., Ilcol, Y. and Gorgul, O.S. (2003) Hepatic effects of halothane, isoflurane or sevoflurane anaesthesia in dogs. J. Vet. Med., 50(10): 530-533.

24. Singh, R., Peshin, P.K., Patil, D.B., Sharda, R., Singh, J., Singh, A.P. and Sharifi, D. (1994) Evaluation of halothane as an anaesthetic in camels. J. Am. Vet. Med. Assoc., 41: 359-68.

25. Bodh, D., Singh, K., Gopinathan, A., Mohindroo, J. and Saini, N.S. (2013) Comparative evaluation of halothane and isoflurane maintenance anesthesia in water buffaloes (Bubalus bubalis). J. Appl. Anim. Res., 42(3): 269-277. 